\title{
Optical profilometer with confocal chromatic sensor for high-accuracy 3D measurements of the uncirculated and circulated coins
}

\author{
Wojciech KAPŁONEK, Marzena SUTOWSKA, Mioriţa UNGUREANU, \\ Kerim ÇETINKAYA
}

DOI: $10.30464 /$ jmee.2018.2.3.181

Cite this article as:

Kapłonek W., Sutowska M., Ungureanu M. Çetinkaya K. Optical profilometer with confocal chromatic sensor for high-accuracy 3D measurements of the uncirculated and circulated coins. Journal of Mechanical and Energy Engineering, Vol. 2(42), No. 3, 2018, pp. 181-192.

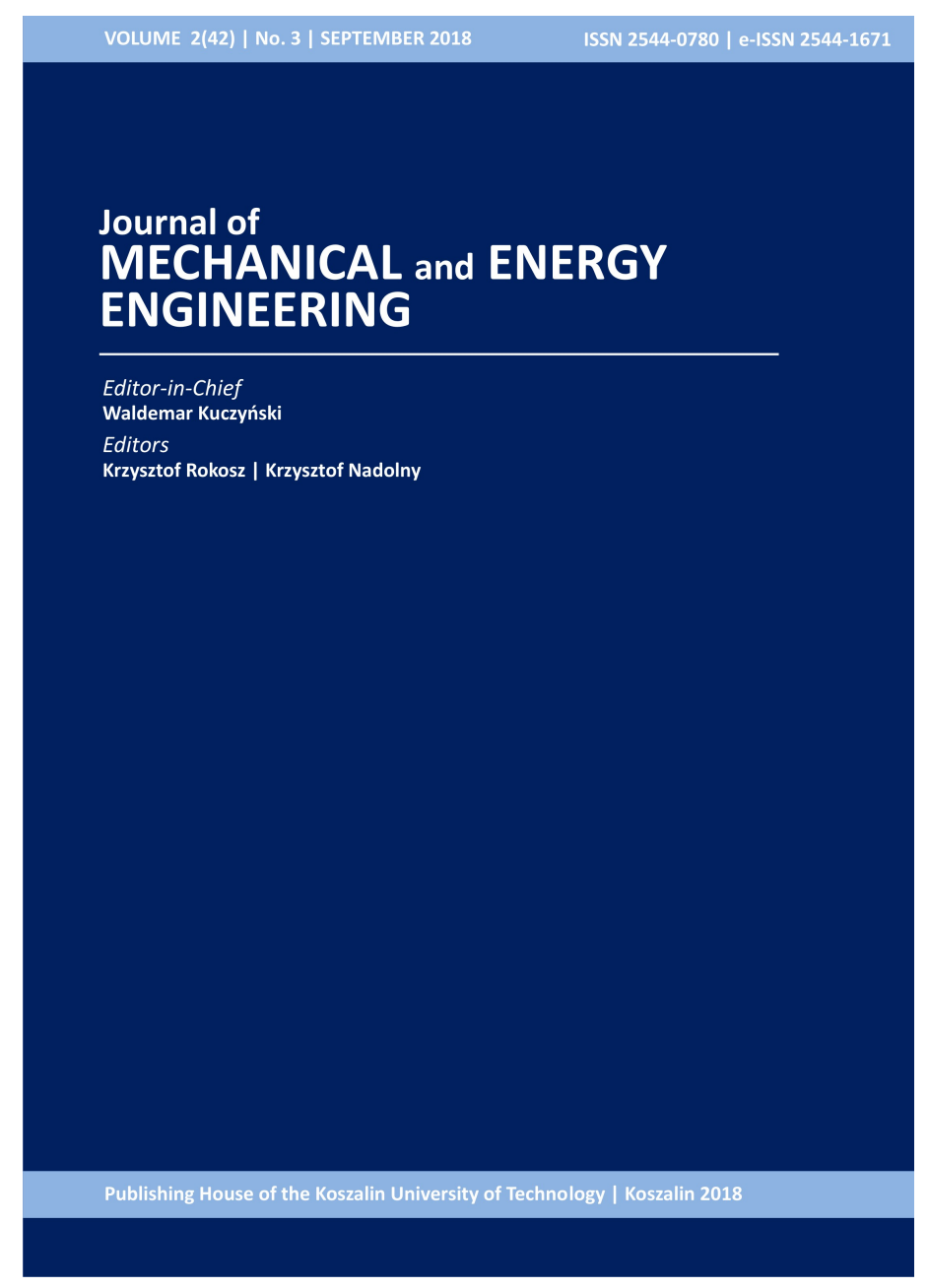

Journal of Mechanical and Energy Engineering

Website: jmee.tu.koszalin.pl

ISSN (Print): 2544-0780

ISSN (Online): 2544-1671

Volume: 2(42)

Number: 3

Year: 2018

Pages: 181-192

Article Info:

Received 28 August 2018

Accepted 20 September 2018

\section{Open Access}

This article is distributed under the terms of the Creative Commons Attribution 4.0 (CC BY 4.0) International License (http://creativecommons.org/licenses/by/4.0/), which permits unrestricted use, distribution, and reproduction in any medium, provided you give appropriate credit to the original author(s) and the source, provide a link to the Creative Commons license, and indicate if changes were made. 


\title{
OPTICAL PROFILOMETER WITH CONFOCAL CHROMATIC SENSOR FOR HIGH-ACCURACY 3D MEASUREMENTS OF THE UNCIRCULATED AND CIRCULATED COINS
}

\author{
Wojciech KAPŁONEK ${ }^{1 *}$, Marzena SUTOWSKA ${ }^{2}$, Mioriţa UNGUREANU ${ }^{3}$, Kerim ÇETINKAYA ${ }^{4}$ \\ ${ }^{1 *}$ Department of Production Engineering, Faculty of Mechanical Engineering, Koszalin University of \\ Technology, Racławicka 15-17, 75-620 Koszalin, Poland, e-mail: wojciech.kaplonek@tu.koszalin.pl \\ ${ }^{2}$ Unconventional HydroJetting Technology Center, Faculty of Mechanical Engineering, Koszalin University of \\ Technology, Racławicka 15-17, 75-620 Koszalin, Poland, e-mail: marzena.sutowska@tu.koszalin.pl \\ ${ }^{3}$ Department of Engineering and Technology Management, Technical University of Cluj Napoca, \\ North University Center of Baia Mare, Dr. Victor Babes 62A, 430083, Baia Mare, Romania \\ ${ }^{4}$ Department of Industrial Design Engineering, Faculty of Technology, Karabük University, \\ Demir-Çelik Kampüsü 78050 Karabük, Turkey, e-mail: kcetinkaya@karabuk.edu.tr
}

(Received 28 Agust 2018, Accepted 20 September 2018)

\begin{abstract}
The term optical profilometry is used in relation to a group of methods used in a rapid, non-destructive, and non-contact assessment of surface topography. Those methods play a significant role in the area of a modern advanced laboratory and industrial 3D measurements. With the development of profilometric methods, a large progress in the construction of optical profilometric instruments and measuring sensors used in them, including confocal sensors based on the chromatic light aberration phenomenon (CLA) has been observed for several years. The paper shows that the Talysurf CLI 2000 multisensory optical profilometer equipped with a CLA sensor can be used in high-accuracy 3D measurements of the uncirculated and circulated coins. The assessment of such type objects characterized by a high variability of altitude can be extremely helpful in analyzing the actual metrological properties of measuring equipment used in their measurements.
\end{abstract}

Keywords: Optical profilometry, confocal chromatic sensor, 3D measurements, surface topography, coin

\section{INTRODUCTION}

The development of many modern machining techniques is accompanied by the dynamic development of new measurement methods, allowing in a wide range of characterization of the properties of the parts being produced, as well as verifying the correctness the shaping of their surface in terms of specific criteria considered in the given case. One of such key criteria is the condition of the surface layer analyzed in relation to the elements of the surface texture (especially surface roughness and waviness). These issues were described in detail in the works of Whitehouse [1] and Leach [2, 3]. The assessment of the abovementioned elements is quite difficult, mainly due to the complex nature of the surface - including occurrence of irregularities with a relatively wide range of the heights. These conditions lead to the need to develop new or a modification and adaptation of existing measurement methods, and thus develop new technical solutions in the field of measuring apparatus, which will allow one to provide the ability to carry out the measurement of the indicated features with high accuracy and in a short time, both in laboratory and industrial conditions.

In 3D surface metrology, according to the ISO EN 25178-6 standard [4], two basic groups of methods dedicated for assessment of the surface texture can be distinguished. These are groups of line profiling and areal topography methods. The first, used in much more cases, includes contact and non-contact (optical) profilometry methods. These methods have been described in detail in many fundamental works from this area presented by Stout [5], Blunt and Jiang [6]. 
One of the dynamically developing for many years groups of areal topography methods are techniques based on optical profilometry including, i.e. light sectioning methods, moiré, optical stylus, confocal, interference and focus-variation microscopy. Wide metrological possibilities, especially in relation of many advanced variants of the last of these methods, described in the works by Mitić et al. [7], D'Acquisto et al. [8], Qu et al. [9], Grimm et al. [10], de Groot [11] and Kapłonek et al. [12], increased the interest of high-accuracy optical measurements in a many industrial applications, which in turn forced the development of a new class of measuring instruments. These aspects, relevant to the review of selected technical solutions used in optical profilometry methods with relation to the construction of instruments and measuring sensors, with a particular emphasis on confocal sensors based on chromatic aberration phenomenon are the main content of this paper. The above considerations have been extended in its final part examples of the use of one of the profilometric instruments - multisensory optical profilometer Talysurf CLI 2000 (TaylorHobson, Leicester, Great Britain) in high-accuracy 3D measurements of the uncirculated and circulated coins.

\section{OPTICAL PROFILOMETRY - INSTRUMENTS AND SENSORS}

First commercial optical profilometers began to emerge in the early 1980s. These instruments were produced by a few companies - Chapman Instruments [13], Wyko [14] and Zygo [15]. The general principle of operation of a such classic instrument was to illuminate the a selected area of examined surface with a focused beam of light, whereby the location of focus of the light wave in relation to this surface was analyzed. The reflected beam returned to the optical system and was directed to photoelectric detectors coupled with the electronic analysis system. The result of operation of such a system was the appropriate transformation of the measurement signal and its visualization in the form of pseudo-colour map, in which the heights of surface irregularities were coded by appropriate color. Detailed description of some of them can be found in the works by Sommargren [16], Makosch and Drollinger [17], Wyant et al. [18] Downs et al. [19], as well as Lange and Bhushan [20].

Over time, optical profilometers, similarly to contact (stylus) instruments, were equipped with motorized $x-y$ measurement stage, intended for the implementation of a high-accuracy measurements of the surface micro- and nanotopography of e.g. optical elements, working standards (gauge blocks), silicon wafers, HDD platters covered with a layer of magnetic carrier. The realization of 3D measurements based on surface scanning could take place not only in the horizontal plane (registration of a single profiles in the $x$ axis, with a shift in the $y$ axis direction), but also in a rotational way (registration of circular and spiral profiles).

Despite of the improvement of optical profilometers designs over the years, their users struggled with the problems resulting from the assessment of the same surface by various measuring methods. In some situations, when the use of the contact (stylus) method was strongly limited, the results obtained had to be supplemented with those registered by other methods. This caused numerous complications resulting from each time calibration of instruments, setting of new parameters for each method, a separate analysis of the obtained data by various types of computer software, etc. As a result, it significantly influenced the time, accuracy and repeatability of measurements as well as the cost of carrying the measurement procedure, hence increased the cost of research work.

The engineers from the leading companies in the field of measuring technology noticing the above mentioned problems undertook actions aimed at developing an instrument combining the possibility of surface texture assessment with various measurement techniques within one hardware platform. In this way, a new class of integrated measuring instruments with a modular construction called optical multi-profilometers or multisensory optical profilometers was developed. These instruments are characterized by an open architecture allowing for the adjustment of appropriate measuring sensors to the specifics of a given measurement task. The big advantage of such a solution is the ability to perform a comprehensive assessment of a given fragment of the analysed surface, which can start from its careful observation using a high-resolution TV camera. Next on the selected area of the surface, contact, non-contact or pseudocontact measurements are carried out (using given type of sensor), and the obtained data is analysed using a computer software. The problem of the appropriate location of the previously observed surface fragment and the implementation of the exact measurement on it is realized by the motorization of all mechanical functions with a special vision system. A concept of such system and other improvements on an example of one of the class of optical profilers - interference microscopes was presented in the work by Freischlad [21].

The family of multisensory optical profilometers Talysurf CLI (Chromatic, Laser, Inductive) produced by British company Taylor-Hobson has been very popular on the global market for several years [22]. In the years 2003-2004, a new class of those type of instruments, designated CLI 500, CLI 1000 and CLI 2000 , respectively was introduced. A general view of the Talysurf CLI 2000 - a leading instrument from this group used by the authors in research works presented in the next section of this paper, alongside a schematic diagram that shows the main units of other instrument form Talysurf family - CLI 1000 is depicted in Fig. 1, 


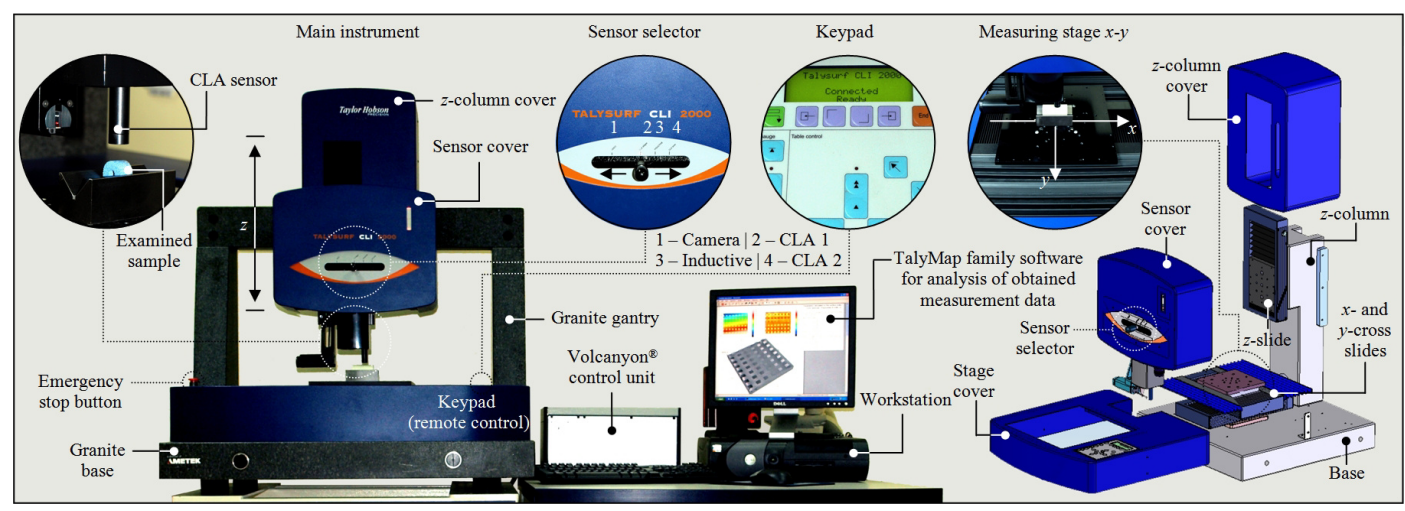

Fig. 1. General view of the multisensory optical profilometer Talysurf CLI 2000 produced by Taylor-Hobson equipped with CLA sensor (left) and schematic diagram showing the main units of Talysurf family instruments on the example of the CLI 1000 (right)

Tab. 1. General specification of the Talysurf CLI family optical profilometers

\begin{tabular}{|c|c|c|c|c|c|c|c|c|}
\hline \multirow[b]{2}{*}{ Instrument } & \multirow{2}{*}{$\begin{array}{c}\text { Measuring } \\
\text { capacity, } \\
\mathrm{mm}^{1)}\end{array}$} & \multicolumn{2}{|c|}{ Axis } & \multirow{2}{*}{$\begin{array}{c}\text { Dimensions } \\
\text { (Main in- } \\
\text { strument), } \\
\mathrm{mm}^{1)}\end{array}$} & \multicolumn{2}{|c|}{ Weight } & \multicolumn{2}{|c|}{ Speed } \\
\hline & & $\begin{array}{c}\text { Travers } \\
\text { length, } \\
\mathrm{mm}^{2)}\end{array}$ & $\begin{array}{c}\text { Resolution, } \\
\mu \mathrm{m}^{3)}\end{array}$ & & $\begin{array}{c}\text { Capacity, } \\
\text { kg }\end{array}$ & $\begin{array}{c}\text { Main in- } \\
\text { strument, kg }\end{array}$ & $\begin{array}{c}\text { Measuring, } \\
\mathrm{mm} / \mathrm{s}\end{array}$ & $\begin{array}{c}\text { Positioning, } \\
\mathrm{mm} / \mathrm{s}^{4)}\end{array}$ \\
\hline CLI 500 & $\begin{array}{c}50 \times 50 \\
\times 50\end{array}$ & 50 & 0.5 & $\begin{array}{c}500 \times 310 \\
\times 450\end{array}$ & 10 & 55 & \multirow{3}{*}{$\begin{array}{c}0.5,1,5 \\
10,15,30\end{array}$} & \multirow{3}{*}{30} \\
\hline CLI 1000 & $\begin{array}{c}100 \times 100 \\
\times 100\end{array}$ & 100 & 0.5 & $\begin{array}{c}500 \times 500 \\
\times 750\end{array}$ & 20 & 105 & & \\
\hline CLI 2000 & $\begin{array}{c}200 \times 200 \\
\times 200\end{array}$ & 200 & 0.5 & $\begin{array}{c}800 \times 800 \\
\times 800\end{array}$ & 29 & 280 & & \\
\hline
\end{tabular}

Tab. 2. Specification of the sensors used in the Talysurf CLI family optical profilometers

\begin{tabular}{|c|c|c|c|c|c|c|c|}
\hline \multicolumn{2}{|c|}{ Sensor } & \multirow{2}{*}{$\begin{array}{c}\text { Scanning } \\
\text { frequency, } \\
\mathrm{Hz}\end{array}$} & \multirow{2}{*}{$\begin{array}{l}\text { Measuring } \\
\text { range, } \mathrm{mm}\end{array}$} & \multicolumn{2}{|c|}{ Resolution } & \multirow{2}{*}{$\begin{array}{l}\text { Measuring } \\
\text { slope, }^{\circ}\end{array}$} & \multirow{2}{*}{$\begin{array}{l}\text { Speed, } \\
\mathrm{mm} / \mathrm{s}\end{array}$} \\
\hline Type & Designation & & & $\begin{array}{l}\text { Vertical, } \\
\mu \mathrm{m}\end{array}$ & $\begin{array}{c}\text { Lateral, } \\
\mu \mathrm{m}\end{array}$ & & \\
\hline Inductive $^{1)}$ & - & - & $\begin{array}{c}0.1,0.5, \\
2.5^{2)}\end{array}$ & $0.002,0.01,0.04^{2)}$ & 2 & 45 & 3 \\
\hline \multirow{2}{*}{ Laser } & LK-031 ${ }^{3)}$ & \multirow{2}{*}{2000} & 10 & 1 & 30 & 40 & \multirow{7}{*}{30} \\
\hline & LK-081 ${ }^{3)}$ & & 30 & 3 & 70 & 25 & \\
\hline \multirow{5}{*}{$\begin{array}{l}\text { Confocal } \\
\text { chromatic }\end{array}$} & RB-300 & \multirow{5}{*}{5000} & 0.3 & 0.01 & 1 & 25 & \\
\hline & RB-400 & & 0.4 & 0.02 & - & - & \\
\hline & RB-800 & & 0.8 & 0.025 & - & $\begin{array}{ll}- \\
-\end{array}$ & \\
\hline & RB-1000 & & 1 & 0.03 & 2 & 20 & \\
\hline & RB-3000 & & 3 & 0.1 & 5 & 13 & \\
\hline
\end{tabular}

${ }^{\text {I) }}$ Sensor is equipped with the stylus $(l=58 \mathrm{~mm}, h=7 \mathrm{~mm})$ with $2 \mu \mathrm{m}$ radius diamond tip, ${ }^{2)}$ Values are selectable, ${ }^{3)}$ Produced by Keyence Corp. (Osaka, Japan)

whereas the general specification of the Talysurf CLI optical profilometers is given in Tab. 1 .

Talysurf profilometers architecture do not differ from the contemporary construction standards used for this type of solutions. The system (in CLI 2000 version) is included an anti-vibration granite base, providing a high-stability, with gantry to which a sensor cover and a vertical slide ( $z$ axis) are mounted. On the base, a motorized measuring stage designed for realization of precise work movement in the $x-y$ axes with keypad for its control and emergency stop button has placed. The measurement process is realized by the use of Talyscan CLI 2000 ver.2.6.1 software provided by the system manufacturer, whereas the visualization of measured surface and analysis of its surface topography is carried out by TalyMap Silver ver. 4.1.2 software, using Mountains Technology ${ }^{\mathrm{TM}}$ (Digital Surf, Besançon, France). The all system ele-ments are operating under the control of an operational controller Volcanyon ${ }^{\circledR}$ (Taylor-Hobson, Leicester, Great Britain). An interesting comparison between above system and NewView100 (Zygo Corp., Middlefield, CT, USA) was presented in the work by Guo et al. [23].

As already mentioned in the optical profilometery, depending on the area of application and the complexity of measurement tasks carried out in its framework, various types of measuring sensors are used. Sensors can generally be divided into three main groups: 


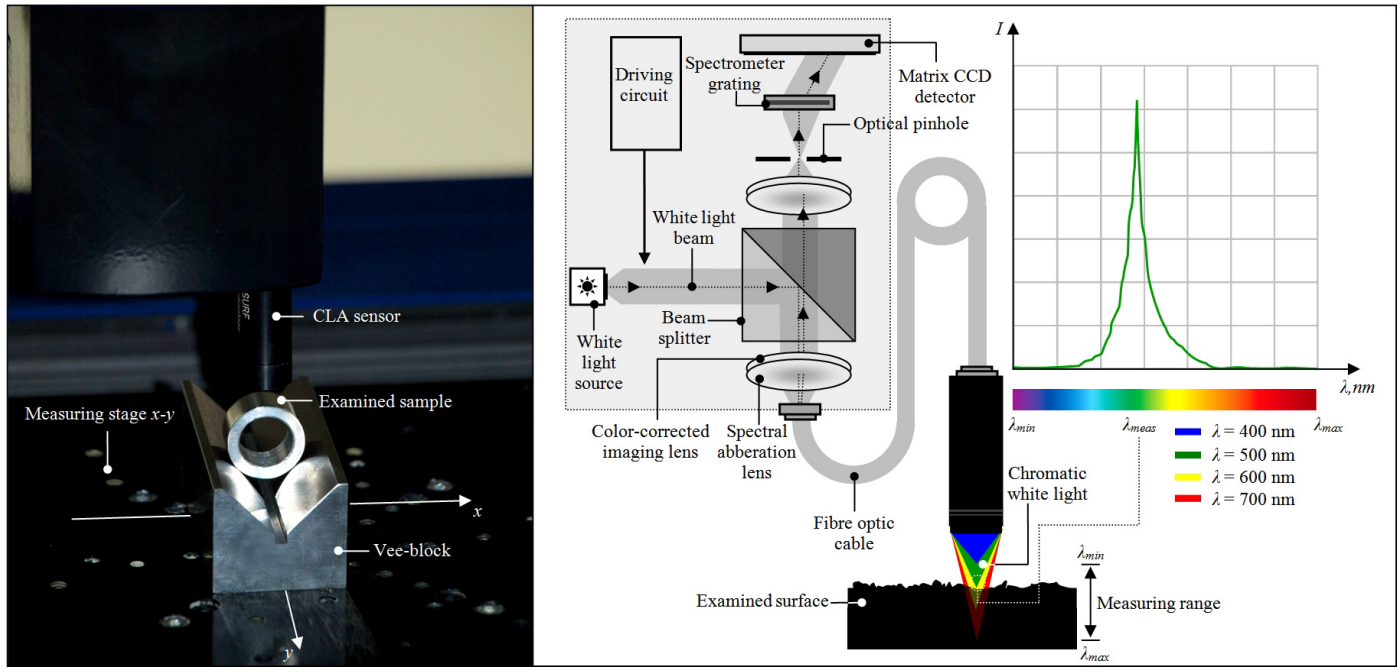

Fig. 2. General view of CLA sensor used in multisensory optical profilometer Talysurf CLI 2000 produced by Taylor-Hobson (left) and schematic diagram showing the operating principles of this sensor based upon the chromatic aberration phenomenon

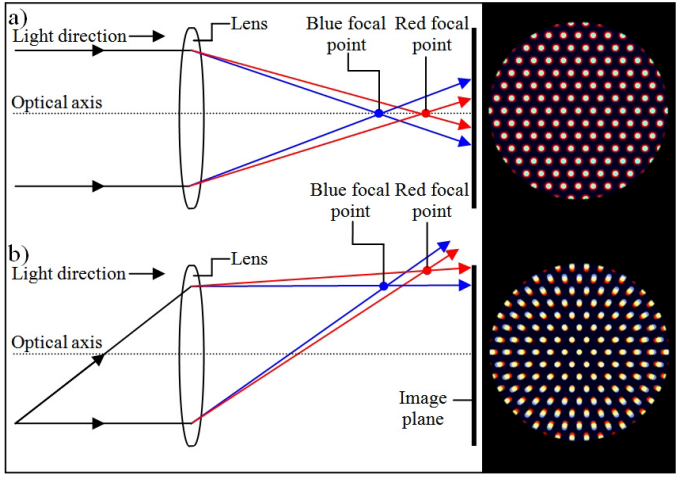

Fig. 3. Schematic diagrams presenting the two forms of chromatic aberration: a) longitudinal chromatic aberration, b) lateral chromatic aberration [26]

- contact, inductive sensor using contact tip made of synthetic diamond with pressure force in a range from 0.6 to $2.0 \mathrm{mN}$ (for conventional materials) or inductive sensor using contact tip with low pressure force $0.01 \mathrm{mN}$ (for soft and brittle materials),

- non-contact (optical), confocal point sensor (CF), confocal chromatic sensor (CLA), triangulation sensor, interference sensor (PSI, VSI), holographic sensor $(\mathrm{CP})$,

- $\quad$ pseudo-contact, integrated module of atomic force microscope (AFM).

The Talysurf CLI 2000 is equipped with a set of three sensors described in detail in the work by Kapłonek et al. [24] and additionally characterized in Tab. 2. One of the most interesting sensors used in optical profilometers is the confocal chromatic sensor (CLA) based on chromatic aberration (also referred as chromatic distortion or spherochromatism). This phenomenon is related with a feature of optical system, which is caused from different distance of focus (due to the different value of the refractive index) for different wavelengths of light, which was presented by Marimont and Wandell in the work [25]. This results in the dispersion of light, which can be visually observe along boundaries of the contrasting areas (dark and bright parts of the image), in the form of a colored "fringes". Chromatic aberration appears in two forms (longitudinal and lateral), presented in Fig. 3 and detail described by MacEvoy in the work [26].

The idea of using the chromatic aberration phenomenon in non-contact profilometric measurements was presented in 1984 by Molesini et al. in the work [27]. Numerous improvements to the measurement method based on this phenomenon introduced by the years to its many variants resulted in developed the ISO EN 25178-602 standard [28] for non-contact instruments using confocal chromatic sensors for measuring surface texture. The principle of the operation of the CLA sensor used in the Talysurf CLI 2000, schematically presented in Fig. 2, consists in illuminating by a white light [29], transported from the source to a beam splitter and next through a spectral aberration lens, of the small area of examined surface. The lens intensifies a chromatic aberration, what resulting in a variable focusing depth. The beam is focused only in one certain point of the surface, which is characterized by a given height of irregularities. The light reflected from the surface is directed to the optical pinhole, that transmits only the beam with a specific wavelength [2]. This situation is extremely beneficial, because eliminates the errors caused by beams with different wavelengths of light. The beam, after passing through the spectrometer grating, deflected the light onto 
Tab. 3. Exemplary areas of applications of the Talysurf CLI family optical profilometers equipped with CLA sensors

\begin{tabular}{|c|c|c|c|c|c|}
\hline \multirow{2}{*}{ Area } & \multirow{2}{*}{ Applications } & \multicolumn{3}{|c|}{ Talysurf CLI } & \multirow{2}{*}{ References } \\
\hline & & 500 & 1000 & 2000 & \\
\hline \multirow{3}{*}{ 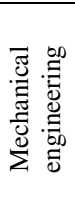 } & $\begin{array}{l}\text { Analyses of the woods surface quality after the } \\
\text { machining process }\end{array}$ & & + & & $\begin{array}{l}\text { Svatoš et al. [30], } \\
\text { Novák et al. [31] }\end{array}$ \\
\hline & $\begin{array}{l}\text { Measurements of the engraved by Nd:YAG laser } \\
\text { cavities of the samples made of wood }\end{array}$ & & & + & Leone et al. [32] \\
\hline & $\begin{array}{l}\text { Measurements of the surface topography of polishing } \\
\text { pads used in CMP process }\end{array}$ & & & + & Guo et al. [33] \\
\hline \multirow{8}{*}{ 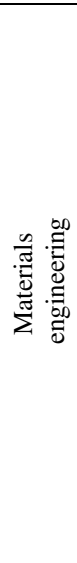 } & $\begin{array}{l}\text { Measurements and analysis of the surface topography } \\
\text { of replicas made from SILOFLEX dental silicone }\end{array}$ & + & & & Kubišová et al. [34] \\
\hline & $\begin{array}{l}\text { Measurements of the surface topography of White } \\
\text { Delrin nylon and timber sample }{ }^{1)}\end{array}$ & & & + & Islam et al. [35] \\
\hline & $\begin{array}{l}\text { Measurements of surface roughness of the RAFM } \\
\text { samples before aluminizing }\end{array}$ & & + & & Purushothaman et al. [36] \\
\hline & $\begin{array}{l}\text { Measurements of topography of the powder } \\
\text { and diamond-coated surfaces }\end{array}$ & & & + & $\begin{array}{c}\text { Barletta [37], Barletta et al. [38], } \\
\text { Polini and Barletta [39] }\end{array}$ \\
\hline & $\begin{array}{l}\text { Measurements of topography of the as-deposited } \\
\text { sample surface (Ti implant) }\end{array}$ & & + & & Komath et al. [40] \\
\hline & $\begin{array}{l}\text { Measurements of surface topography of TiMo } \\
\text { biomedical alloys }\end{array}$ & + & & & Ghiban et al. [41] \\
\hline & $\begin{array}{l}\text { Measurements of worn surface topography of AISI } \\
\text { type } 316 \mathrm{~L}(\mathrm{~N}) \text { steel disc }\end{array}$ & & + & & Parthasarathi et al. [42] \\
\hline & $\begin{array}{l}\text { Surface topography of UAM processed aluminium } \\
\text { substrates }\end{array}$ & & & + & Li et al. [43] \\
\hline
\end{tabular}

${ }^{17}$ Authors used also the inductive (stylus) and laser triangulation sensor

a CCD matrix detector in order to interpolate the spatial position of the mea-sured point. The measurement is realized in a confocal configuration in which the extended focusing depth is obtained by the use of chromatic color coding and spectral interferometry.

The currently manufactured CLA sensors have a relatively high sensitivity and a high range of focusing depth, which are their undoubtedly their big advantages relation to other sensor types. The typical measuring range is usually from $\sim 0.3 \mathrm{~mm}$ (in some devices even from $0.1 \mathrm{~mm}$ ) to $\sim 60 \mathrm{~mm}$ (resolution of $\sim 0.005-0.9 \mu \mathrm{m}$ ).

Additional advantages of CLA sensors are their wide measurement possibilities in relation to a various types of surfaces characterized by a low height of the surface irregularities (smooth and super-smooth surfaces after finish machining) and a high height of the surface irregularities (conventionally used elements made of metals and its alloys, plastics as well as rubber) as well as transparent and semi-transparent surfaces (elements made of glass and plastics). The small diameter of the light spot (usually from $\sim 3.5 \mu \mathrm{m}$ to $\sim 100 \mu \mathrm{m}$ ) allows for the measurement of a complicated and cumbersome electronic components, such as: small diameter wires, pins on PCBs and connectors.

The above mentioned advantages predispose to use CLA sensors in many areas of laboratory and industry-oriented application, in which fast and highaccuracy assessments of the analyzed surfaces realized in a non-contact way is needed. Some of these areas, on the example of using the Talysurf CLI family optical profilometers equipped with CLA sensors, are presented in Tab. 3.

\section{EXPEIMRNTAL STUDIES}

Determining the actual metrological capabilities of a given measuring instrument is a rather complex issue. It depends on parameters of used instrument, type and features of analyzed object (e.g. its geometry, surface characteristics) and the adopted measurement methodology. To determine such capabilities, a wide range of measurements of various types of typical and untypical objects supported by a proper interpretation of obtained results should be carried out.

The surface measurements of the coins are interesting in this case. On these objects (on obverse and reverse side) a many of convex or concave elements (e.g. legend, motto, design, mint mark) characterized by a wide dimensional range are appear. The assessment of such a relatively complex surface, from a point of view of its dimensions and shape, gives an interesting opportunities for testing both measurement procedures and subsequent determination of the metrological capability of the measuring instrument used.

In this section, selected results of experimental studies of uncirculated and circulated coins obtained using the multisensory optical profilometer Talysurf CLI 2000 produced by Taylor-Hobson equipped with CLA sensor are presented. The authors showed several representative examples of various analyzes possible to realized by the TalyMap Silver ver. 4.1.2 software, based on data obtained from the measuring instrument. 


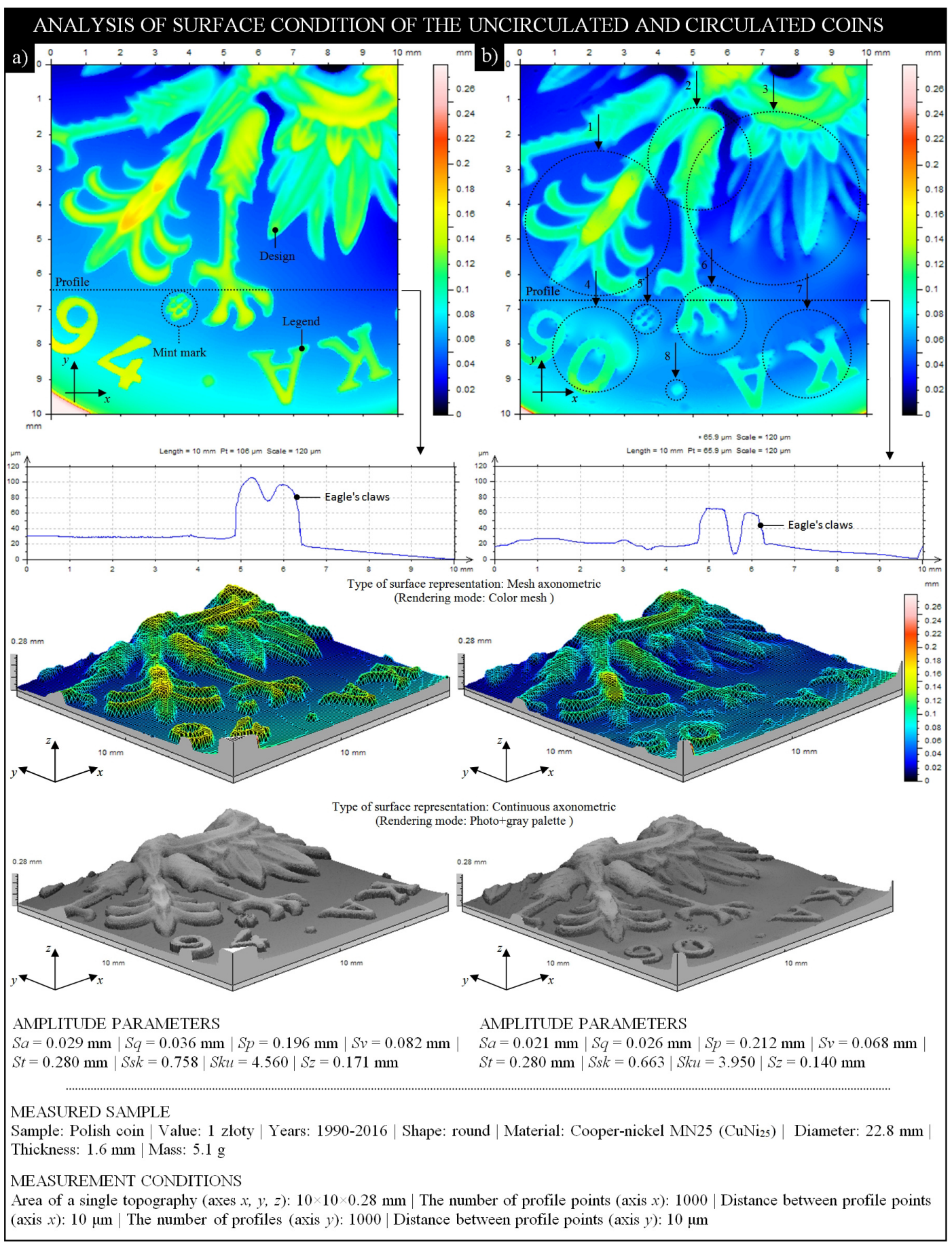

Fig. 4. The collection of results obtained by advanced optical profilometer Talysurf CLI 2000 equipped with CLA gauge for obverse surface of the coin (County: Poland, Value: $1 \mathrm{zl}$ ) in a condition: a) uncirculated (without visible surface wear); b) circulated (with visible slight surface wear - worn areas of the coin marked as 1-8) [43]

All presented examples were extended by a detailed commentary. In Fig. 4 a collection of results obtained for two polish coins (value: $1 \mathrm{zl}$, issue year: 1990 and 1994) [43], are presented. Coin from Fig. 4a was in a un-circulated condition, whereas coin from
Fig. 4b circu-lated. The collection included the following features (from top to the bottom): 2D pseudo-color surface map (indexed colors) with extracted a single profile, 3D surface topography (in representation as a mesh and continues axonometry), 


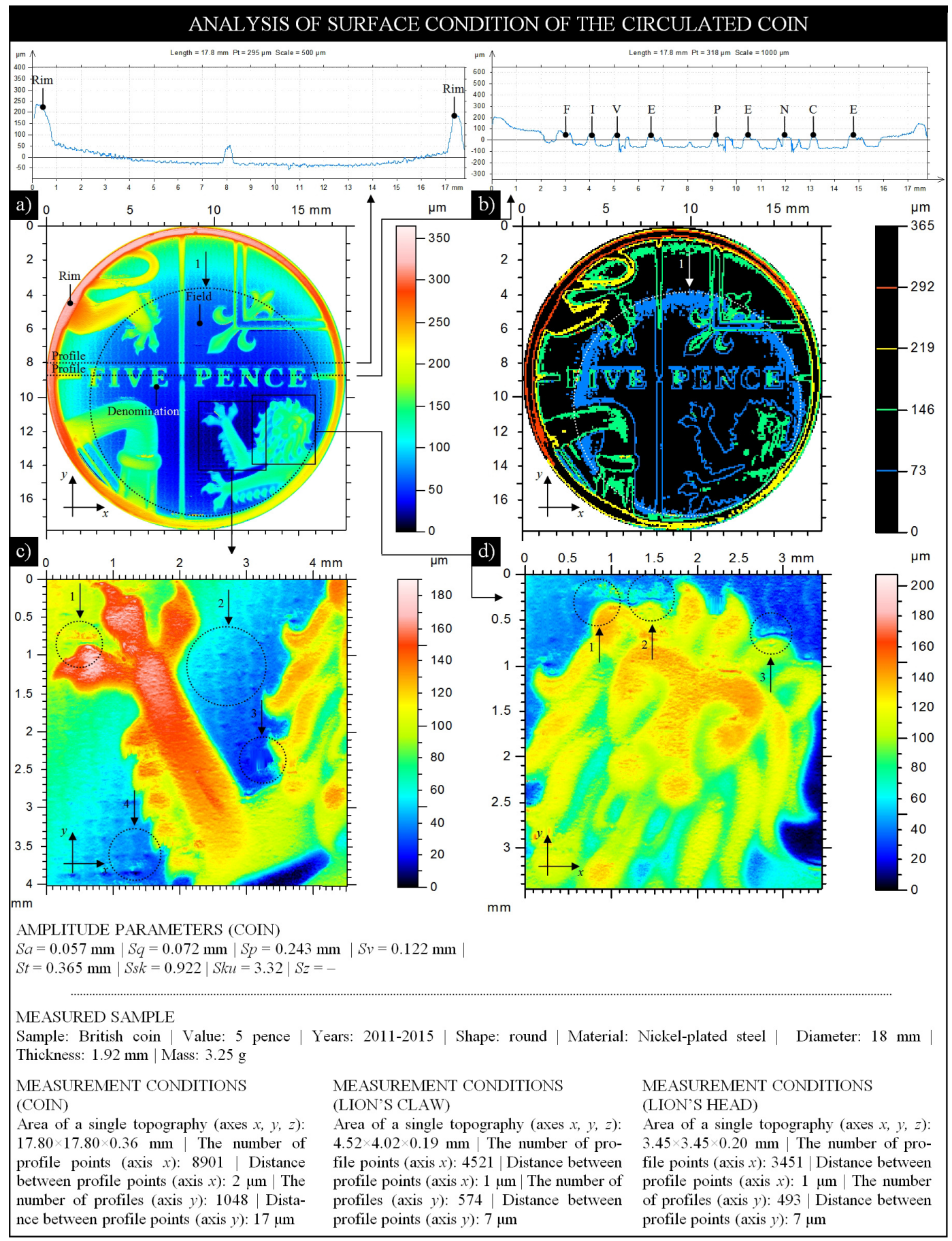

Fig. 5. The collection of results obtained by advanced optical profilometer Talysurf CLI 2000 equipped with CLA gauge for reverse surface of the circulated coin (County: Great Britain, Value: 5 pence): a) 2D pseudo-color surface map (indexed colors) with extracted a two single profiles (above); b) contour diagram; c) extracted from Fig. 5a surface area $(4.52 \times 4.02 \mathrm{~mm})$ with marked worn areas $1-4 ; \mathrm{d})$ extracted from Fig. 5a surface area $(3.45 \times 3.45 \mathrm{~mm})$ with marked worn areas $1-3$

values of selected 3D surface texture (amplitude) parameters as well as brief information related to measured sample and measure-ment conditions. The presented obvervations are interesting due to the possibility of detailed study of changes in their geometry caused by wear. In this case, it is worth comparing identical fragment $(10 \times 10 \mathrm{~mm})$ of both coins for which a 2D pseudo-color surface map was 


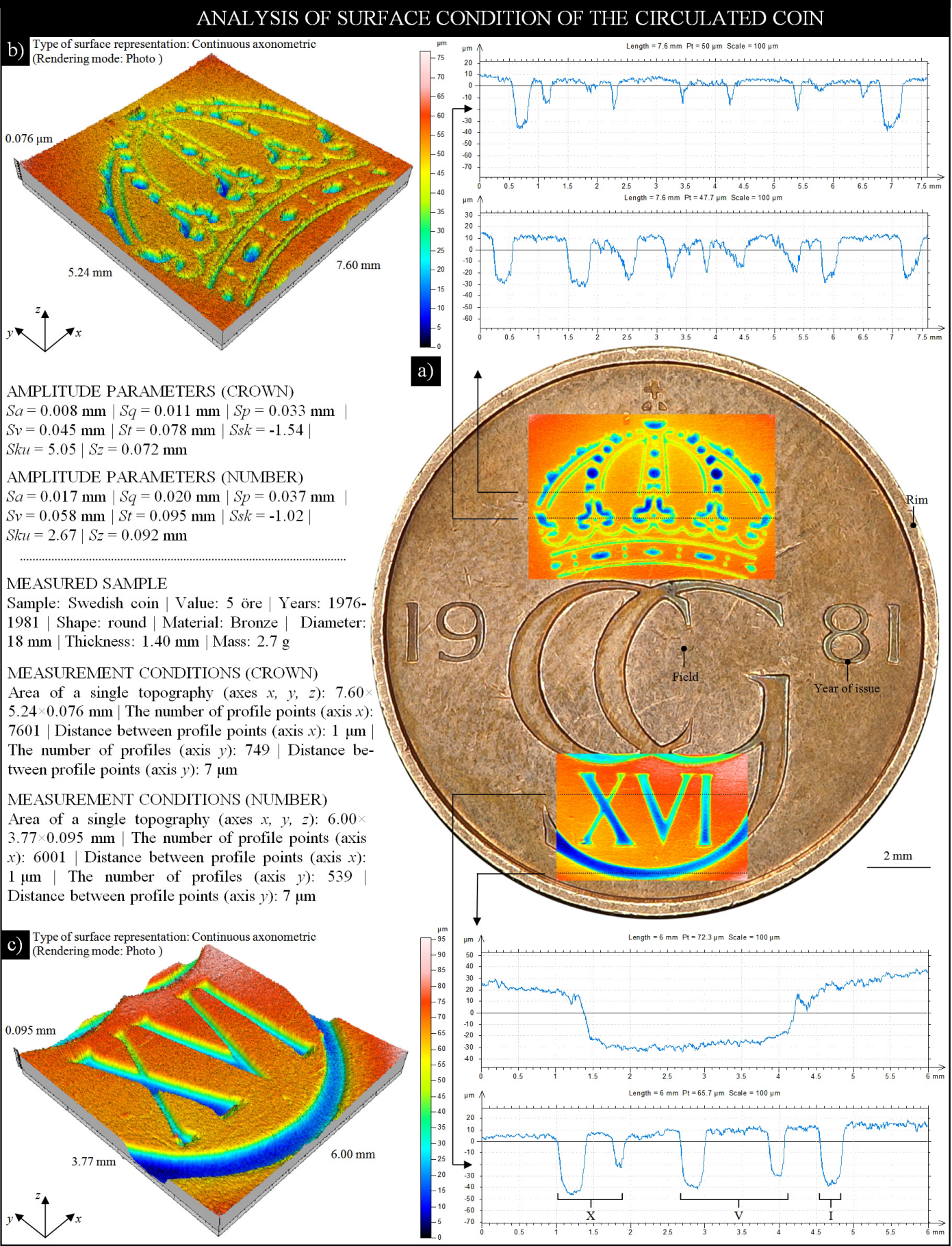

Fig. 6. The collection of results obtained by advanced optical profilometer Talysurf CLI 2000 equipped with CLA gauge for obverse surface of the circulated coin (County: Sweden, Value: 5 öre): a) image fusion of real image of the coins surface and a two 2D pseudo-color surface maps (indexed colors) with extracted a pair of single profiles (above and below); b) 3D surface topography (in representation as a continues axonometry) of the crown located at upper area of the coin $(7.60 \times 5.24 \mathrm{~mm})$; c) 3D surface topography (in representation as a continues axonometry) of the roman number XVI located at lower area of the coin $(6.00 \times 3.77 \mathrm{~mm})$

generated as a result of measurement. Maxi-mum height of the surface elements (design, legend) in the uncirculated coin doesn't exceed $0.21 \mathrm{~mm}$, while for the circulation coin it is smaller by $0.04 \mathrm{~mm}$, which confirms the occurrence on it a relatively low-level of the wear. It is particularly visible in the areas marked 
on the surface of the circulation coin, which included a numerous elements e.g. design (1-3, 6), legend $(4,7$, 8) and mint mark (5). The only areas of comparable height are the internal areas around design for which the wear was minimal.

Below the half of both 2D pseudo-color surface maps, two single profiles were extracted (profile type: West-East, point: 637). They present a fragment of the base surface (field) of a coin with a length of $10 \mathrm{~mm}$ and a slope of $3.5^{\circ}$, which is directed towards the rim. In the half, the each profile is intersect by a fragment of the design (eagle's claws) with a height $h=0.106 \mathrm{~mm}$ (uncirculated coin) and $h=0.065 \mathrm{~mm}$ (circulated coin), respectively. Analysis of these both profiles clearly shows on which level the worn of the circulated coin was occurred and consequently, the distortion of the profile of the base surface (field) and the design. The height of this element measured for the circulated coin was lower by $38 \%$ in relation to uncirculated coin.

The above results were complemented by a collection of a 3D surface topographies. Combination of surface representation (mesh and continuous axonometry) and rendering mode (color mesh and photo+gray palette) enable to a proper surface visualization, which is useful when observing those areas that are characterized by the occurrence of significant wear. Also in Fig. 4 the values of selected 3D surface texture (amplitude) para- meters detailed information about the analyzed samples and measurement conditions were additionally given.

In Fig. 5 a collection of results obtained for British coin (value: 5 pence, issue year: 2011), are presented. The general view of the coin in circulated condition presented in a form of $2 \mathrm{D}$ pseudo-color surface map (indexed colors) is shown in Fig. 5a. In the central part of the coin, a vast area of relatively slight (in terms of surface height) wear is clearly visible. This circular area $(13.78 \times 13.78 \mathrm{~mm})$ was marked (1) in Fig. $5 \mathrm{a}$ as well as (1) in Fig. 5b, which presenting surface of the coin in a form of contour diagram. The height on the diagram, in the range $0-365 \mu \mathrm{m}$, is sliced for four levels. The surface wear corresponds to the lowest level $-73 \mu \mathrm{m}$.

From the Fig. 5a, a two single profiles were extracted (profile type: West-East, point: 456 and 519). First profile present a fragment of the base surface (field) with rim and a part of design element in its center. The rim at left side of the coin characterized by a much higher height $(h=248.23 \mu \mathrm{m})$, than the rim at right side $(h=198.78 \mu \mathrm{m})$, what indicates the creating of the wear in this direction. Second profile present a fragment of the base surface (field) and denomination. The lettering FIVE PENCE is characterized by $h_{\text {mean }}=98.38 \mu \mathrm{m}$. From this same image, the two areas located at the right-bottom of the coin and presenting one of the element of the Royal Shield - the lion were also extracted. The lion was divided into two individual subareas depicted in Fig. 5c $(4.52 \times 4.02 \mathrm{~mm})$ and Fig.
$5 \mathrm{~d}(3.45 \times 3.45 \mathrm{~mm})$ in a form of $2 \mathrm{D}$ pseudo-color surface maps (indexed colors). Within of this fragment of the coins surface there are also located areas, which are characterized by the occurring of the wear. These areas were marked (1-4), (1-3) respectively. Similarly to Fig. 4, additional information related with selected 3D surface texture (amplitude) parameters as well as detailed description of the analyzed sample and measurement conditions were also given.

In Fig. 6 a collection of results obtained for Swedish coin (value: 5 öre, issue year: 1981), are presented. For a better visualization of its wear authors prepared an image fusion (Fig. 6a), which is a combination of real image of the coins surface with a two 2D pseudo-color surface maps (indexed colors). The maps were obtained for a two characteristic elements - the crown, located at upper area of the coin $(7.60 \times 5.24 \mathrm{~mm})$ and the roman number XVI, located at lower area of the coin $(6.00 \times 3.77 \mathrm{~mm})$.

A visual analysis of the coins surface indicates that it was in circulation. There are minor distortions of all its elements. This applies to both field as well as the device and the rim. In addition, several small scratches of varying length and depth are visible. Obtained 2D pseudo-color surface maps (indexed colors) expressly indicate the occurrence of worn out areas. The differrence between heights of these areas is in a range 20 to $30 \mu \mathrm{m}$. From both maps a two pairs of a single profiles for a parts of crown (profile type: West-East, point: 474 and 616) and parts of roman number XVI (profile type: West-East, point: 227 and $683)$ were extracted as well as, additionally a $3 D$ surface topographies (in representation as a continues axonometry) (Fig. 6b and Fig. 6c, respectively). The complement of the above analyzes, as in the case of those shown in Fig. 4 and Fig. 5, are values of selected 3D surface texture (amplitude) parameters calculated for area from Fig. $6 \mathrm{~b}$ and Fig. 6c, respectively, detailed information about the analyzed samples as well as measurement conditions.

\section{CONCLUSIONS}

On the basis of the experimental studies related with the analysis of possibilities of using the multisensory optical profilometer Talysurf CLI 2000 produced by Taylor-Hobson equipped with CLA sensor in measurements of the uncirculated and circulated coins, the following detailed conclusions can be drawn:

- a number of challenges posed by modern branches of manufacturing industry in relation to metrological equipment cause the efforts of its manufacturers to continuously improve the measurement and analysis methods;

- an important area of modern industrial measurements are 3D surface texture measurements realized by wide range of areal topography 
methods based on optical profilometry including, i.e. light sectioning methods, moiré, optical stylus, confocal, interference and focus-variation microscopy;

- optical profilometers play dominant role in accurate 3D surface texture measurements. For over 20 years, group of a multisensory optical profilometers are successfully used. These instruments connect usually a few measurement methods as part of one hardware platform, what is a big advantage of such solution. An example of such an instrument, described in detail in this work (Section 2), was multisensory optical profilometer Talysurf CLI 2000 (Tab. 1), equipped with confocal chromatic sensor (CLA) based on chromatic aberration pheno- menon (Tab. 2);

- the authors presented the measurement possibilities of the above instrument in relation to the surface assessment of the uncirculated and circulated coins (Section 3). These objects are particularly interesting with metrological point of view due to the presence of many convex or concave elements on their surfaces, which characterized by a high varia-lbility of altitude and shape;

- assessment of the coins surface realized by optical profilometry methods, e.g. in the field of recognition and analysis of areas containing defects and above all wear, may be helpful in the selection of an appropriate mint alloy with increased durability and resistant for wear.

\section{Acknowledgements}

The authors wish to thank Mr. Marcin Surman MSc, BSc for use selected research results in this paper, Mr. Krzysztof Maciejewski from the Laboratory of Metrology and Measurement Systems for laboratory supervision and consultations regarding the interpretation of obtained measurement results as well as Mr. Mariusz Władowski from Optotom for interesting discussions and valuable comments concerning measurements by multisensory optical profilometers.

\section{Nomenclature}

$$
\begin{aligned}
& \text { Symbols } \\
& h \quad-\text { height, } \mu \mathrm{m} \\
& S a \quad-\text { arithmetic mean deviation of the surface, } \mu \mathrm{m} \\
& S q \quad-\text { root mean square height, } \mu \mathrm{m} \\
& S p \quad-\text { maximum height of peaks, } \mu \mathrm{m} \\
& S v \quad-\text { maximum height of valleys, } \mu \mathrm{m} \\
& S t \quad-\text { total height of the surface, } \mu \mathrm{m} \\
& S s k \quad-\text { skewness of height distribution, - } \\
& S k u \quad-\text { kurtosis of height distribution, - }
\end{aligned}
$$

\section{Acronyms}

AFM - Atomic Force Microscopy(e)
CCD - Charge-Coupled Device

$$
\begin{array}{ll}
\text { CF } & \text { - Confocal Point Sensor } \\
\text { CP } & \text { - Holographic Sensor } \\
\text { CLA } & \text { - Chromatic Light Aberration Phenomenon } \\
\text { CLI } & \text { - Chromatic, Laser, Inductive } \\
\text { CMP } & \text { - Chemical Mechanical Planarization } \\
\text { HDD } & \text { - Hard Disc Drive } \\
\text { ISO } & \text { - International Organization for Standardization } \\
\text { LTCC } & \text { - Low Temperature co-Fired Ceramics Technology } \\
\text { Nd:YAG } & \text { - Neodymium-doped Yttrium Aluminum Garnet } \\
\text { PCB } & \text { - Printed Circuit Board } \\
\text { PSI } & \text { - Phase Scanning Interferometry(ter) } \\
\text { RAFM } & \text { - Reduced Activation Ferritic Martensitic } \\
\text { UAM } & \text { - Ultrasonic Additive Manufacturing } \\
\text { VSI } & \text { - Vertical Scanning Interferometry(ter) }
\end{array}
$$

\section{Terminology}

Circulated - term used in relation to coin, which is currently or was in the past in circulation as a means of payment (money). Such coin is usually characterized by a various condition of the surfaces wear.

Denomination - proper description of a currency amount for coins or banknotes.

Design (Device) - pattern or emblem used in the coin.

Field - background area of the coin without pattern, emblem or inscription.

Legend - principal inscription on the coin.

Mint mark - small letter (or other symbol), indicating in which mint the coin was manufactured under the government authority.

Motto - word, sentence or phrase inscribed on a coin to express a guiding national principle.

Obverse - front or heads side of the coin.

Reverse - back or tails side of the coin.

Rim - raised portion of the design along the edge that protects the coin from wear.

Uncirculated - theoretically, a coin that has never circulated and thus retains all of its original mint condition.

\section{References}

1. Whitehouse D.J. (2010) Handbook of surface and nanometrology (2nd Ed.). CRC Press, Boca Raton.

2. Leach (Ed.) R. (2011). Optical measurement of surface topography. Springer, Berlin and Heidelberg.

3. Leach R. (Ed.) (2013). Characterisation of areal surface texture. Springer, Berlin and Heidelberg.

4. ISO EN 25178-6:2010 (2010). Geometrical Product Specifications (GPS) - Surface texture: Areal - Part 6: Classification of methods for measuring surface texture. European Committee for Standardization. Genève.

5. Stout K.J. (Ed.) (2002). Development of methods for characterisation of roughness in three dimensions. Penton Press, London.

6. Blunt L., Jiang X. (2003). Advanced techniques for assessment surface topography. Kogan Page Science, London.

7. Mitić J., Anhut T., Meier M., Ducros M., Serov A., Lasser T. (2003). Optical sectioning in wide-field microscopy obtained by dynamic structured light illumination and detection based on a smart pixel detector array. Optics Letters, Vol. 28, No. 9, pp. 698-700.

8. D'Acquisto L., Fratini L., Siddiolo A.M. (2002). A modified moiré technique for three-dimensional surface topography. Measurement Science and Technology, Vol. 13, No. 4, pp. 613-622. 
9. Qu X.H., Zhao X.H., Ye S.H. (2005). Defocusing detection of geometric sizes in micro-machining. Key Engineering Matererials, Vol. 295-296, pp. 125-132.

10. Grimm T., Wiora G., Witt G. (2015). Characterization of typical surface effects in additive manufacturing with confocal microscopy. Surface Topography: Metrology and Properties, Vol. 3, No. 1, p. 014001.

11. de Groot P. (2015). Principles of interference microscopy for the measurement of surface topography. Advances in Optics and Photonics, Vol. 7, No. 1, pp. 1-65

12. Kapłonek W., Nadolny K., Królczyk G.M. (2016). The use of focus-variation microscopy for the assessment of active surfaces of a new generation of coated abrasive tools. Measurement Science Review, Vol. 16, No. 2, pp. 42-53.

13. Bristow T.C., Arackellian K. (1987). Surface roughness measurements using a Nomarski type scanning instrument. Proceedings SPIE, Vol. 749, pp. 114-118.

14. Bhushan B., Wyant J.C., Koliopoulos C.L. (1985). Measurement of surface topography of magnetic tapes by Mirau interferometry. Applied Optics, Vol. 24, No. 10, pp. 1489-1497.

15. Leonhardt K., Rippert K.H., Tiziani H.J. (1989). Optical methods of measuring rough surfaces. Proceedings SPIE, Vol. 1009, pp. 22-29.

16. Sommargren G.E. (1981). Optical heterodyne profilometry. Applied Optics, Vol. 20, No. 4, pp. 610-618.

17. Makosch G., Drollinger B. (1984). Surface profile measurement with a scanning differential $\mathrm{AC}$ interferometer. Applied Optics, Vol. 23, No. 24, pp. 4544-4553.

18. Wyant J.C., Koliopoulos C.L., Bhushan B., George O.E. (1984). An optical profilometer for surface characterization of magnetic media. ASLE Transactions, Vol. 27, pp. 101-113.

19. Downs M.J., McGivern W.H., Ferguson H.J. (1985) Optical system for measuring the profiles of supersmooth surfaces. Precision Engineering, Vol. 7, No. 4, pp. 211215.

20. Lange S.R., Bhushan B. (1988). Use of two-and threedimensional, noncontact surface profiler for tribology applications. Surface Topography, Vol. 1, No. 3, pp. 277290.

21. Freischlad K. (2010). Optical surface profiling: Profilometer advances benefit surface analysis, film-thickness measurement. Laser Focus World, Vol. 46, pp. 1-1. Retrieved May 3, 2018, from https://www.laserfocus-world. com/articles/print/volume-46/issue-1/features/opticalsurface-profiling.html

22. Elmas S., Islam N., Jackson M.R., Parkin R.M. (2011). Analysis of profile measurement techniques employed to surfaces planed by an active machining system. Measurement, Vol. 44, No. 2, pp. 365-377.

23. Guo D.M., Qin N., Kang R.K., Jin Z.J. (2008). Novel measurement technique on 3D surface topography of polishing pad. Advanced Materials Research, Vol. 53-54, pp. 265-272.

24. Kapłonek W., Nadolny K., Tomkowski R., Valíček J. (2012). High-accuracy surface topography measurements of abrasive tools using a 3D optical profiling system. Measurement Automation and Monitoring, Vol. 58. No. 5, pp. 443-447.

25. Marimont D.H., Wandell B.A. (1994). Matching color images: the effects of axial chromatic aberration. Journal of the Optical Society of America A, Vol. 11, No. 12, pp. 3113-3122.

26. MacEvoy B. (2013). Astronomical Optics. Retrieved May 3, 2018, from https://www.handprint.com/ASTRO/ae4.html

27. Molesini G., Pedrini G., Poggi P., Quercioli F. (1984). Focus-wavelength encoded optical profilometer. Optics Communications, Vol. 49, No. 4 , pp. 229-233.
28. ISO EN 25178-602:2010 (2010). Geometrical Product Specifications (GPS) - Surface texture: Areal - Part 602: Nominal characteristics of non-contact (confocal chromatic probe) instruments. European Committee for Standardization, Genève.

29. Ali S.H. (2012). Advanced nanomeasuring techniques for surface characterization. ISRN Optics, ID 859353, pp. 1-23.

30. Svatoš M., Kopecký Z., Rousek M. (2014). Effects of the technolology of machining on the surface quality of selected wood. Acta Universitatis Agriculturae et Silviculturae Mendelianae Brunensis, Vol. 59, No. 6, pp. 329-336.

31. Novák V., Rousek M., Kopecký Z. (2011). Assessment of wood surface quality obtained during high speed milling by use of non-contact method. Drvna Industrija, Vol. 62, No. 2, pp. 105-113.

32. Leone C., Lopresto V., Iorio De I. (2009). Wood engraving by Q-switched diode-pumped frequency-doubled Nd: YAG green laser. Optics and Lasers in Engineering, Vol. 47, No. 1, pp. 161-168.

33. Guo D.M., Qin N., Kang R.K., Jin Z.J. (2008). Novel measurement technique on 3D surface topography of polishing pad. Advanced Materials Research, Vol. 53-54, pp. 265272.

34. Kubišová M., Pata V., Sýkorová L., Hýlová L., Šuba O. (2018). Multi-parameter surface-quality analysis. Materials and Technology, Vol. 52, No. 1, pp. 23-26.

35. Islam N., Parkin R.M., Jackson M.R., Kesy Z. (2011). Development of a novel profile measurement system for actively planed surfaces. Measurement, Vol. 44, No. 2 , pp. 466-477.

36. Purushothaman J., Ramaseshan R., Albert S.K., Rajendran R., Gowrishankar N., Ramasubbu V., Murugesan S., Dasgupta Arup, Jayakumarba T. (2010) Influence of surface roughness and melt superheat on HDA process to form a tritium permeation barrier on RAFM steel. Fusion Engineering and Design, Vol. 101, pp. 154-164.

37. Barletta M. (2009). Combined use of scratch tests and CLA profilometry to characterize polyester powder coatings. Surface and Coatings Technology, Vol. 203, No. 13, pp. 1863-1878.

38. Barletta M., Bolelli G., Guarino S., Lusvarghi L., (2007). Development of matte finishes in electrostatic (EFB) and conventional hot dipping (CHDFB) fluidized bed coating process. Progress in Organic Coatings, Vol. 59, No. 1, pp. 53-67.

39. Polini R., Barletta M. (2008). On the use of $\mathrm{CrN} / \mathrm{Cr}$ and $\mathrm{CrN}$ interlayers in hot filament chemical vapour deposition (HF-CVD) of diamond films onto WC-Co substrates. Diamond and Related Materials, Vol. 17, No. 3, pp. 325-335.

40. Komath M., Rajesh P., Muraleedharan C.V., Varma H.K., Reshmi R., Jayaraj M.K. (2001). Formation of hydroxyapatite coating on titanium at $200^{\circ} \mathrm{C}$ through pulsed laser deposition followed by hydrothermal treatment. Bulletin of Materials Science, Vol. 34, No. 2, pp. 389-399.

41. Ghiban A., Jimenez Ballesta A.E., Gonzalez Morales N., Pirvulescu L.D., Ghiban B., Tiganescu T.V. (2016). Heat treatment influence on the wear behavior of TitaniumMolybdenum biomedical alloys. Materiale Plastice, Vol. 53, No. 3, pp. 485-490.

42. Parthasarathi N.L., Utpal Borah, Albert S.K. (2013). Effect of temperature on sliding wear of AISI $316 \mathrm{~L}(\mathrm{~N})$ stainless steel-Analysis of measured wear and surface roughness of wear tracks. Materials \& Design, Vol. 51 pp. 676-682.

43. Li J., Monaghan T., Masurtschak S., Bournias-Varotsis A., Friel R.J., Harris R.A. (2015). Exploring the mechanical strength of additively manufactured metal structures with 
embedded electrical materials. Materials Science and Engineering A, Vol. 639, pp. 474-481.

44. Surman M. (2014). Design project of the coin orientation unit in the sorting device (MSc thesis). Koszalin University of Technology, Koszalin, Poland.

\section{Biographical notes}

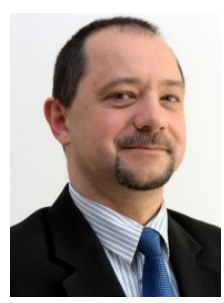

Wojciech Kapłonek (ORCID 00000003-4531-8963) received his M.Sc. degree in Mechanics and Machine Design (specialization: Computer Applications in Engineering), Ph.D. degree (with honors) and D.Sc. in Machinery Construction and Operation (specialisation: Technical Metrology) from the Koszalin University of Techno-logy (Koszalin, Poland) in 2003, 2010 and 2018, respectively. Since 2007 he has been a researcher in the Department of Production Engineering at the Koszalin University of Technology, where currently he works as an associate professor. He has participated in 2 international and 3 national research projects, as well as presenting results from his work at 6 international and 28 national conferences. His research interests focus on problems concerning 2D-3D measurements of surface roughness using optical methods (especially those, which utilise light scattering phenomenon), various variants of the light and electron microscopy, machine vision systems, as well as image processing and analysis techniques. He is author and co-author of 2 monographs and more than 120 scientific papers in various international and national journals, book chapters and conference proceedings.

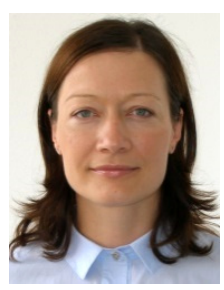

Marzena Sutowska received her M.Sc degree in Mechanics and Machine Design and Ph.D. degree in Machinery Construction and Operation from the Koszalin University of Technology, in 2002 and 2009, respectively. Since 2006 to 2013 she was a scientific and technical specialist (2012-2013 - she held the position of Head of the Fundamental Research Team) in Unconventional Hydro Jetting Technology Institute at the Koszalin University of Technology. Since 2014 she has didactic-research position in the Unconventional HydroJetting Technology Center at the Koszalin University of Technology, where currently she works as an Assistant Professor (2015 - held the duties of Director of the Centre). Her scientific work focuses on modern processing processes, including the curvilinear machining of various materials using a high-pressure abrasive water jet, as well as on the analysis and evaluation of surface quality obtained as a result of the impact of the water and abrasives on the processed material. She has published scientific papers in international and national journals, monographs chapters as well as conference proceedings.

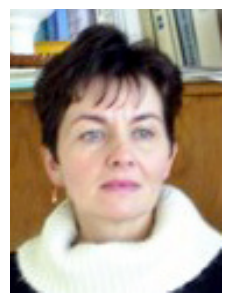

Miorița Ungureanu (ORCID 00000002-5427-5857) received her B.Sc. degree in Mechanical Engineering (specialization: Machines and Mining Installations) from Technical University of Petroșani (Petroşani, Romania) in 1989, M.Sc. degree in Management and Business Administration (speciali-zation: Management) from Northern University Centre of Baia Mare (Baia Mare, Romania) in 2008 as well as Ph.D. degree in Engineering (specialization: Mechanics-Tribology) from North University of Baia Mare (Baia Mare, Romania) in 2004. Since 206 she has been a researcher in Department of Engineering and Technology Management at the North University Centre of Baia Mare, where currently she works as an assistant professor. Her current research interest are covered with selected issues from area of tribology (wear and friction of materials), non-destructing testing and metrology (measurements of surface roughness) as well as product innovation management. She published more than 50 scientific papers from those areas.

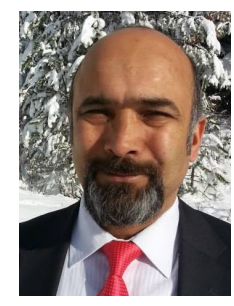

Kerim Çetinkaya (ORCID 00000001-9537-1821) received his M.Sc. and Ph.D. degree in Mechanical Education from Graduate School of Natural And Applied Sciences, Gazi University (Ankara, Turkey) in 1989 and 1995, respectively. Since 2005 he has been a professor in the Department of Industrial Design Engineering at the Karabük University (Karabük, Turkey), where currently he is the head of this department. He has organised 1 international Design Engineering symposium and 3 international 3D Printing Technologies congresses, as well as presenting results of his work at several international and national conferences. His research interests focus on 3D printer design and applications, design and prototype CNC lathes and milling, bio-composite-waste recycling, sheet metal forming, moulding-recycling polymers, design for manufa-cturing professional design applications, transport systems design. $\mathrm{He}$ is author and co-author of 4 books and more than 100 scientific papers in various international and national journals, book chapters and conference proceedings. 